\title{
Study on the Magneto-Structural Correlation of a New Dinuclear Cobalt(II) Complex with Double $\mu$-Phenoxo Bridges
}

Xiao-jiao Song* and Xiao-ming Xue

Key Laboratory of National Forest and Grassland Administration on Wildlife Evidence

Technology, School of Criminal Science and Technology, Nanjing Forest Police

College, Nanjing 210023, P. R. China.

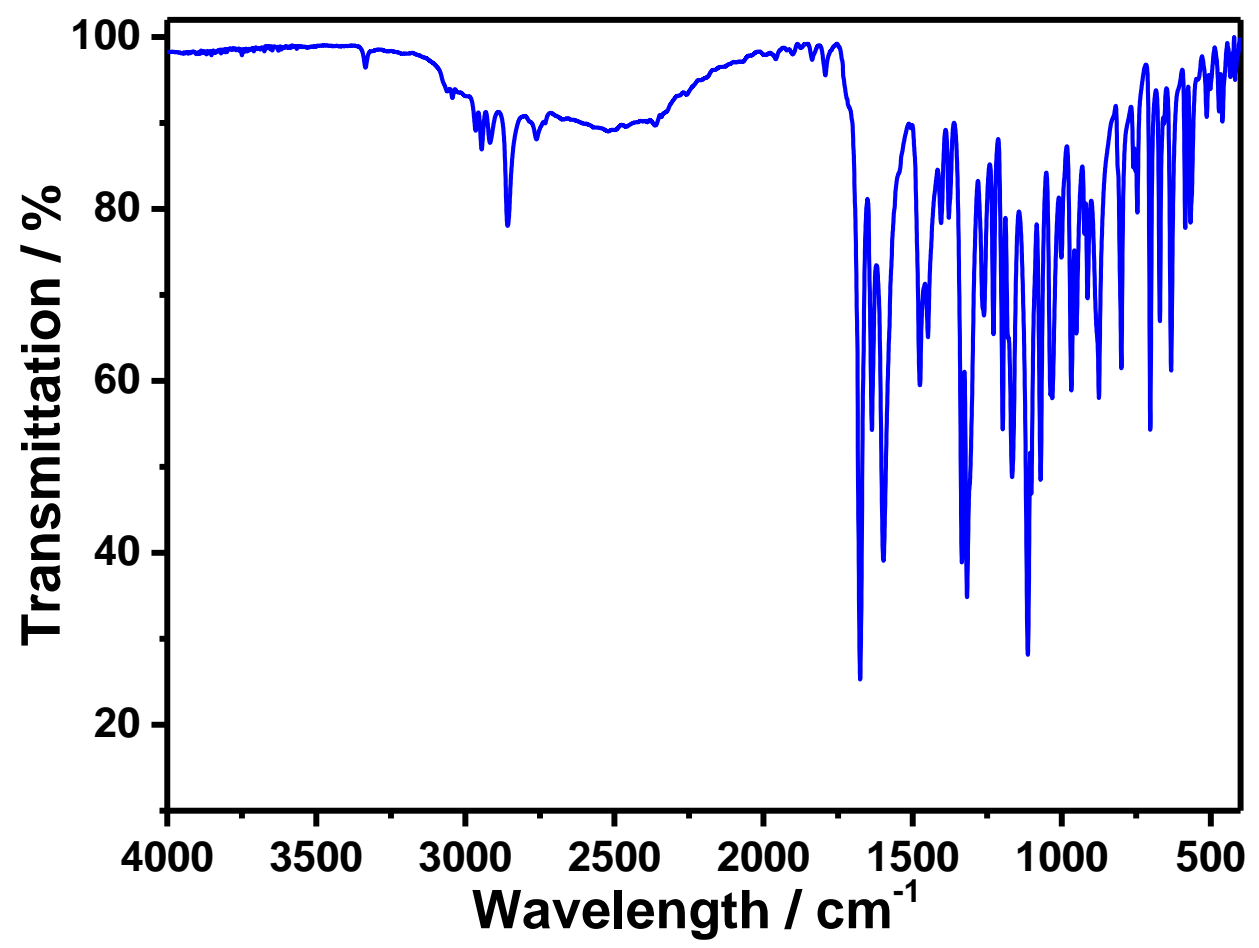

Figure S1 IR spectra of ligand HL. 


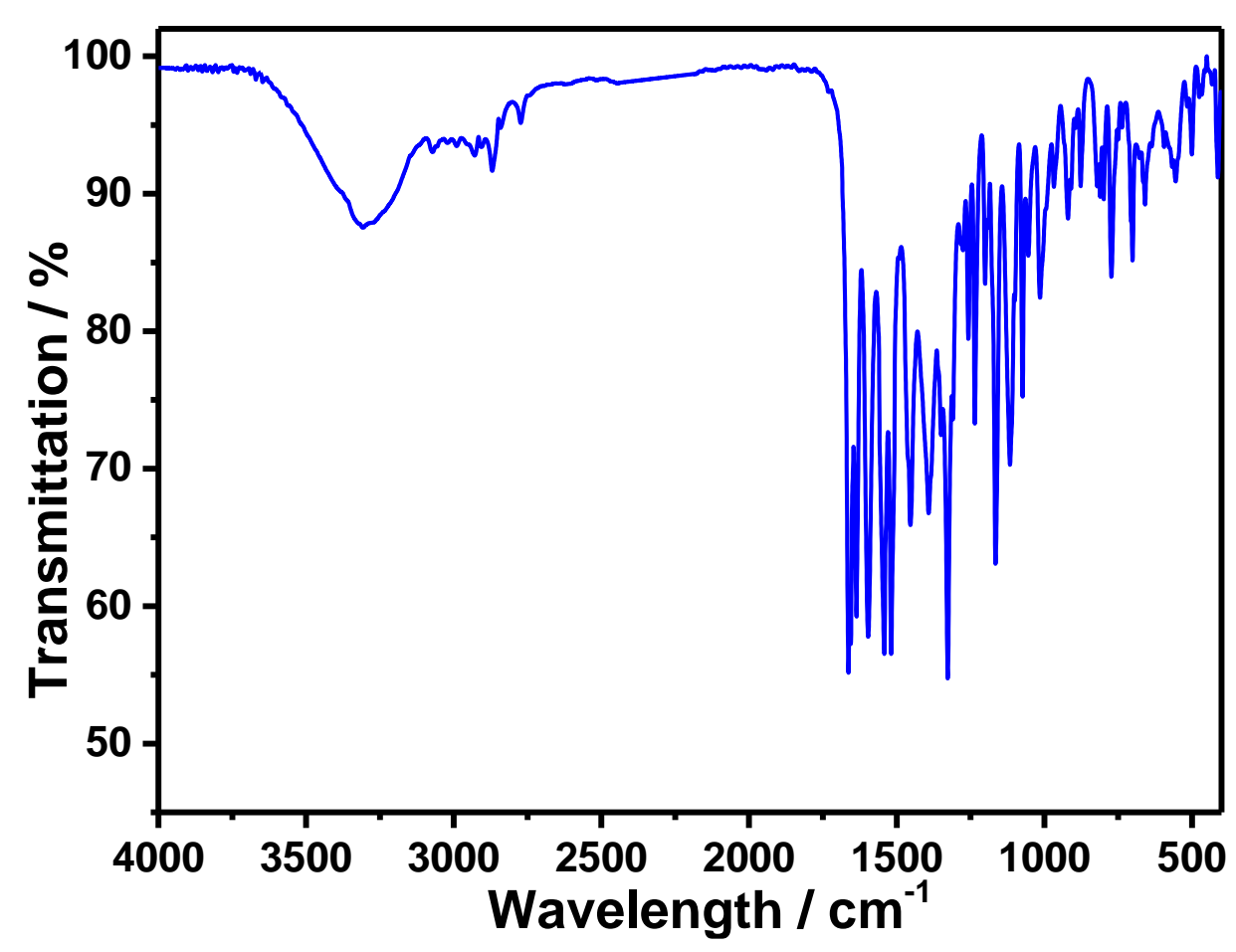

Figure S2 IR spectra of ligand complex 1.

Table S1 Selected bond lengths and angles of ligand HL

\begin{tabular}{lccc}
\hline \multicolumn{4}{l}{ Bond lengths $[\AA]$ and bond angles [deg] } \\
\hline $\mathrm{O} 1-\mathrm{C} 1$ & $1.217(4)$ & $\mathrm{F} 1-\mathrm{C} 17$ & $1.336(4)$ \\
$\mathrm{O} 2-\mathrm{C} 8$ & $1.340(3)$ & $\mathrm{F} 2-\mathrm{C} 17$ & $1.335(4)$ \\
$\mathrm{N} 1-\mathrm{C} 9$ & $1.282(4)$ & $\mathrm{F} 3-\mathrm{C} 17$ & $1.334(4)$ \\
$\mathrm{N} 1-\mathrm{C} 10$ & $1.472(4)$ & & \\
$\mathrm{C} 9-\mathrm{N} 1-\mathrm{C} 10$ & $118.9(3)$ & $\mathrm{N} 1-\mathrm{C} 9-\mathrm{C} 7$ & $121.4(3)$ \\
\hline
\end{tabular}

Table S2 The hydrogen bonding interactions in ligand HL and complex 1.

\begin{tabular}{|c|c|c|c|c|}
\hline D-H $\cdots A$ & $\mathbf{D}-\mathbf{H}(\AA)$ & $\mathbf{H} \cdots \mathbf{A}(\AA)$ & $\mathbf{D} \cdots \mathbf{A}(\AA)$ & D-H$\cdots A(\operatorname{deg})$ \\
\hline HL & & & & \\
\hline $\begin{array}{l}\mathrm{O} 2-\mathrm{H} 2 \cdots \mathrm{N} 1 \\
\text { complex1 }\end{array}$ & 0.820 & 1.838 & 2.567 & 147.22 \\
\hline O9-H9B $\cdots$ O8 & 0.891 & 1.857 & 2.705 & 158.13 \\
\hline O9-H9A $\cdots$ O6(i) & 0.893 & 2.091 & 2.756 & 130.51 \\
\hline
\end{tabular}

Symmetry transformations: $(i)=-x+1 / 2,-y+3 / 2,-z+1$ 
Table S3 SHAPE 2.1 analysis of six-coordinate geometry of Co(II) ions in complex 1.

\begin{tabular}{cccccc}
\hline & HP(D6h) & PPY(C5v) & OC(Oh) & TPR(D3h) & JPPY(C5v) \\
\hline Co1 & 20.667 & 23.862 & 7.742 & 19.484 & 24.373 \\
Co2 & 22.545 & 24.215 & 6.859 & 18.142 & 24.892 \\
\hline
\end{tabular}

Abbreviations: HP-Hexagon, PPY-Pentagonal pyramid, OC-Octahedron, TPR-

Trigonal prism, JPPY-Johnson pentagonal pyramid (J2).

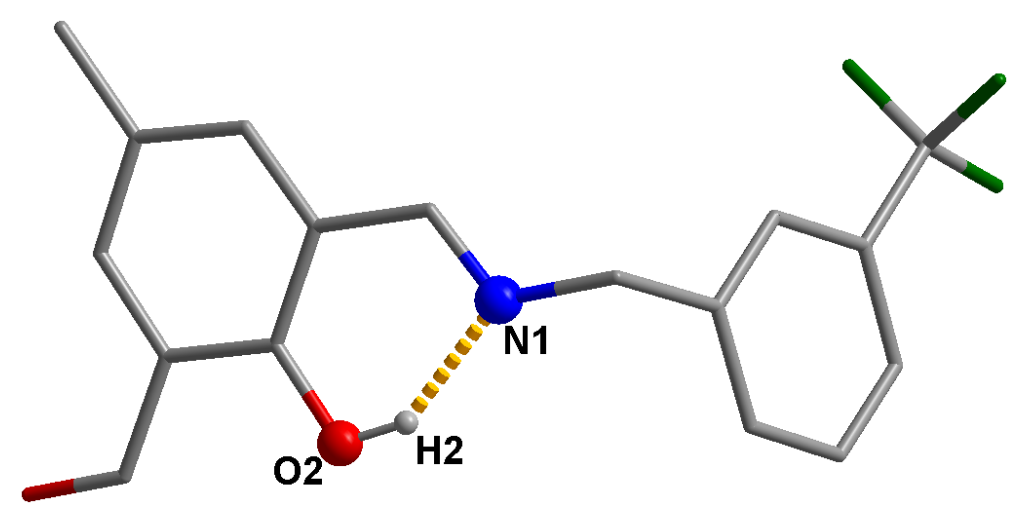

Figure S3 View of the structure of HL with the H-bonding interactions.

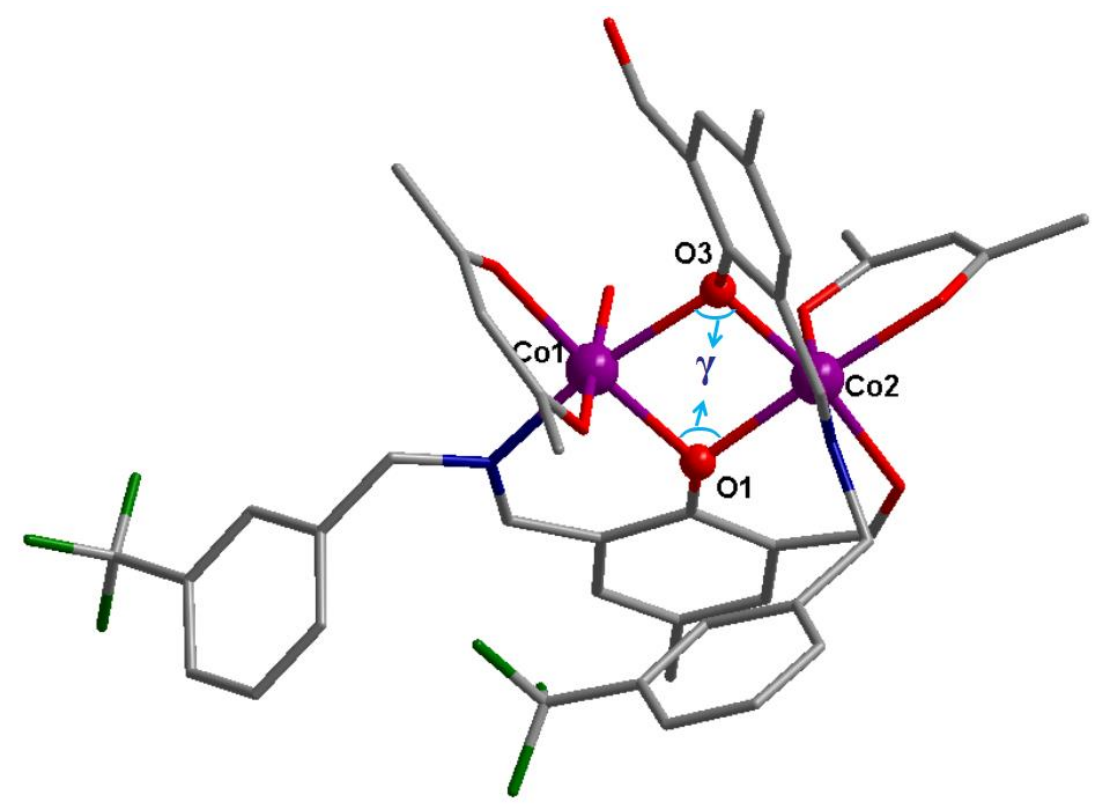

Figure $\mathbf{S 4}$ The Co-O-Co angle is recorded as $\gamma$, the $\gamma_{\mathrm{Co1}-\mathrm{O} 1-\mathrm{Co2}}$ is $96.96(11)^{\circ}$ and $\gamma_{\mathrm{Co2}-\mathrm{O} 3-}$ Co1 is $96.91(11)^{\circ}$. 

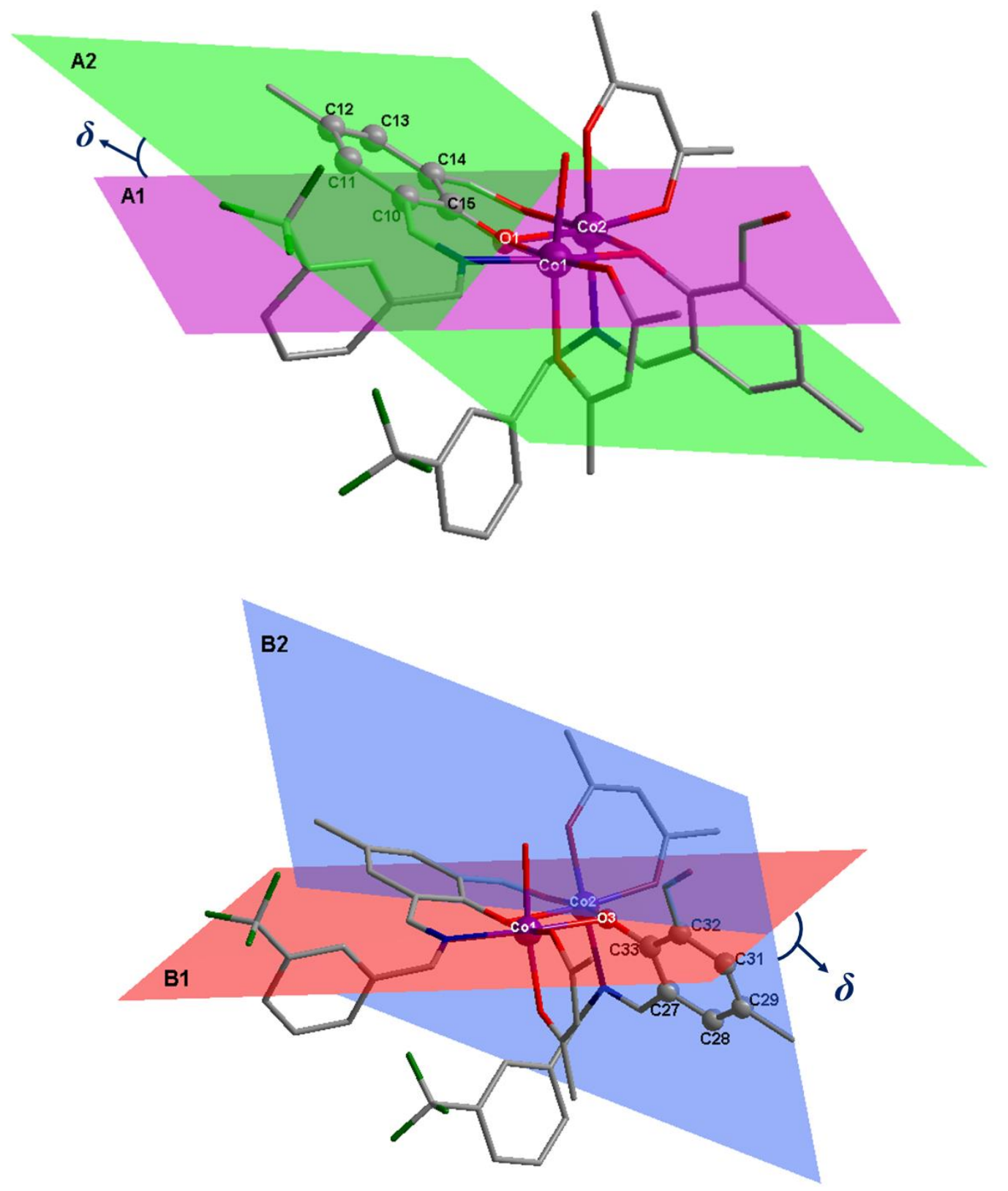

Figure S5 The dihedral angle between the CoOCo plane and the phenyl plane is record as $\delta$. Top: the dihedral angle between the plane A1 formed by phenoxo ring $\mathrm{C} 10 \mathrm{C} 11 \mathrm{C} 12 \mathrm{C} 13 \mathrm{C} 14 \mathrm{C} 15$ and plane $\mathrm{A} 2$ formed by $\mathrm{Co} 1 \mathrm{O} 1 \mathrm{Co} 2, \delta=30.6^{\circ}$. Bottom: the dihedral angle between the plane B1 formed by phenoxo ring C27C28C29C31C32C33 and plane $\mathrm{B} 2$ formed by $\mathrm{Co} 1 \mathrm{O} 3 \mathrm{Co} 2, \delta=63.06^{\circ}$. 


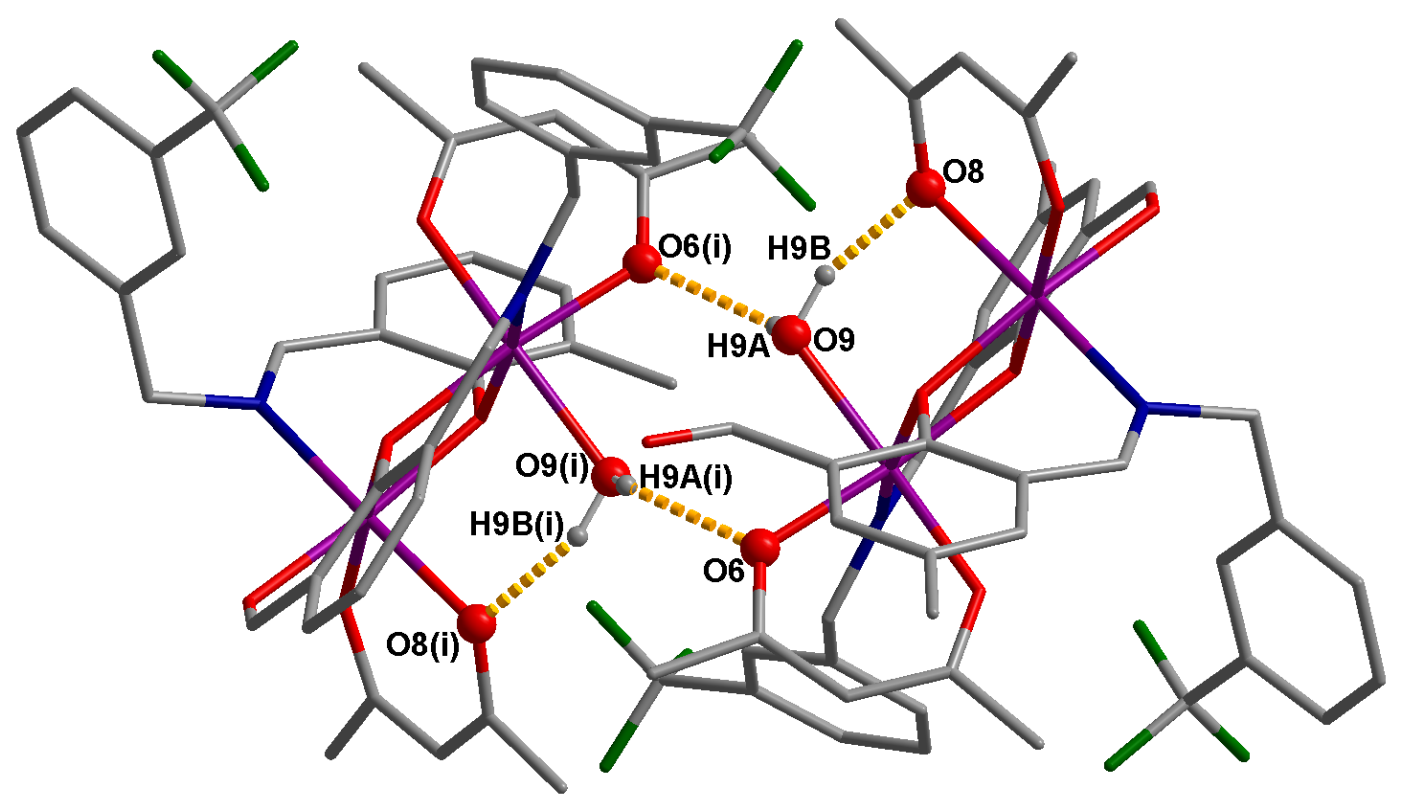

Figure S6 View of two-molecule cluster formed by the H-bonding interactions in complex 1. Symmetry transformations: $(i)=-x+1 / 2,-y+3 / 2,-z+1$.

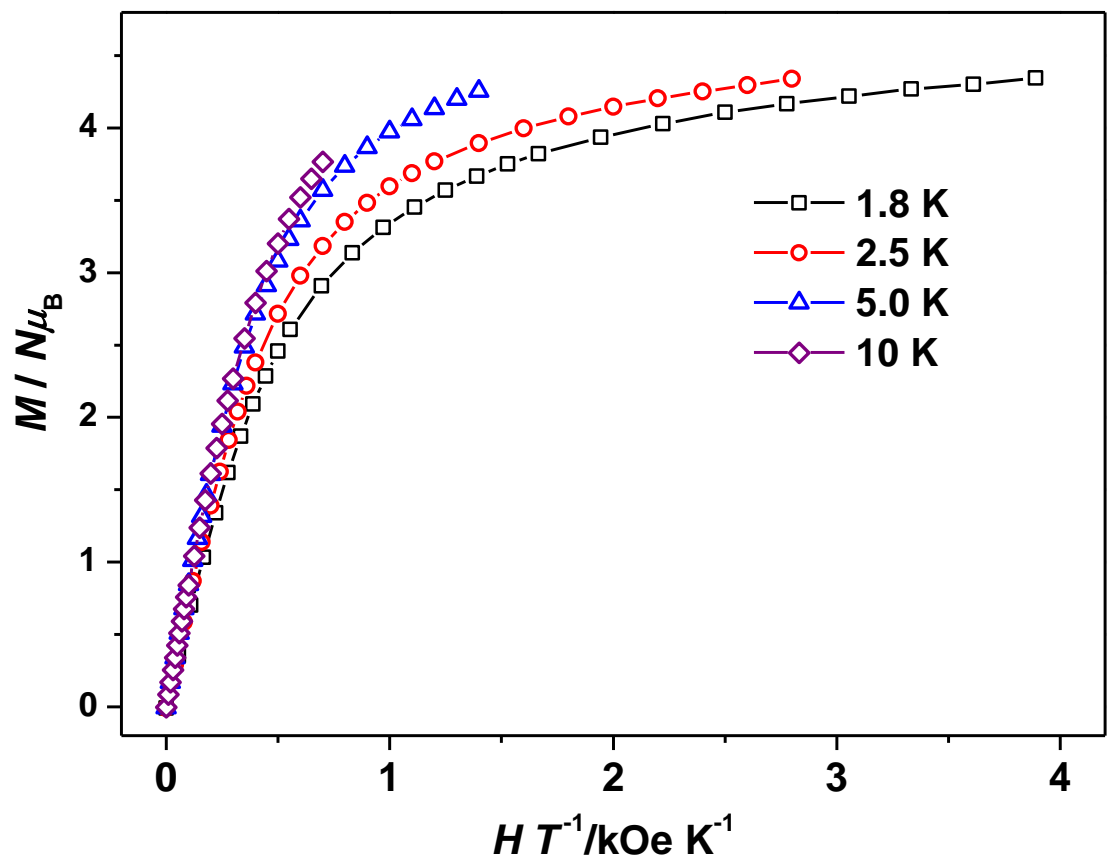

Figure $\mathbf{S} 7$ The plots of $M$ verss $H / T$ at different temperatures for complex $\mathbf{1}$. 


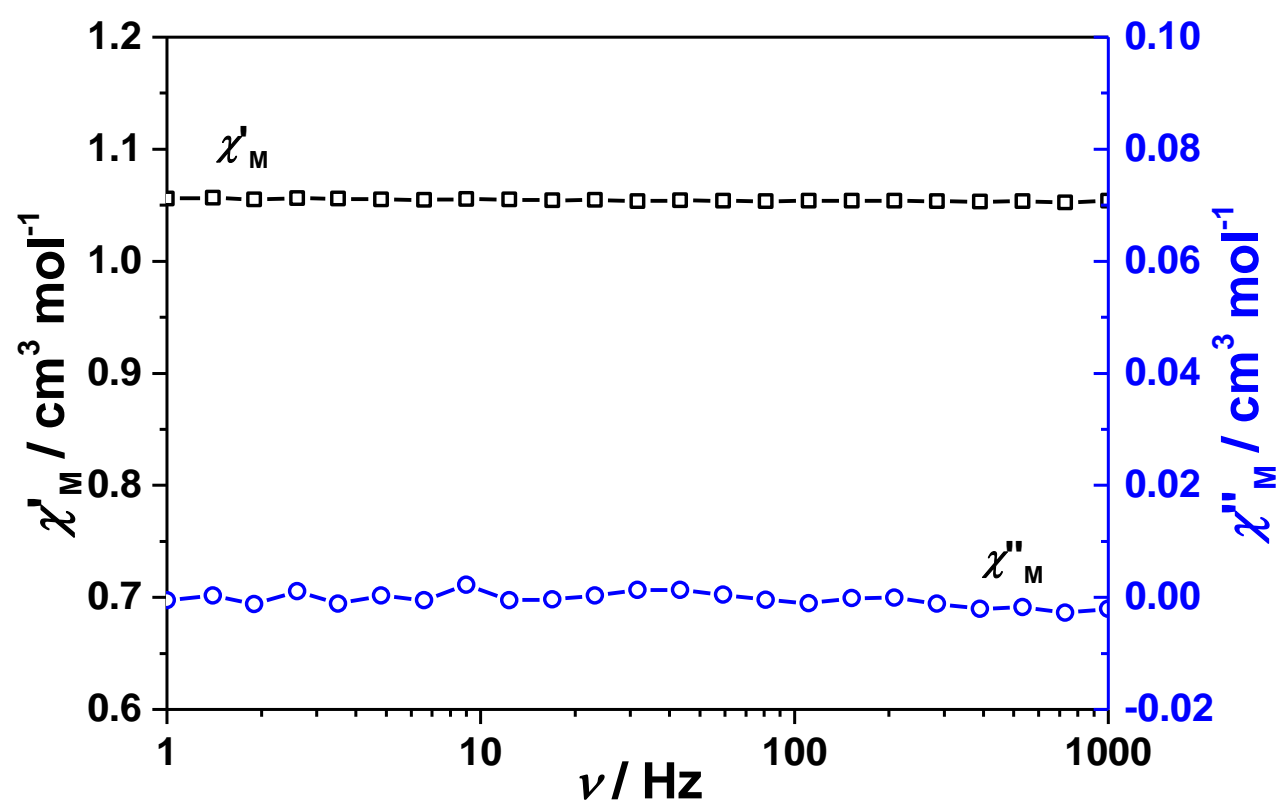

Figure S8 Variable-Frequency in-phase $\left(\chi_{M^{\prime}}\right)$ and out-of-phase $\left(\chi_{M}{ }^{\prime \prime}\right)$ components of the ac magnetic susceptibility under 0 Oe dc field at $2.0 \mathrm{k}$ for $\mathbf{1}$. 